\title{
Prognostic Significance of Electrocardiographic Changes in Diphtheria Myocarditis: A Cross-Sectional Study
}

\author{
Karnakar Rapolu1 ${ }^{1}$, Krishna Malakonda Reddy Parvathareddy ${ }^{1}$, Suneetha Karumuri ${ }^{1}$, \\ Srinivasa Polasa ${ }^{1}$, Ashok Thakkar² \\ ${ }^{1}$ Department of Cardiology, Osmania General Hospital \& Osmania Medical College, Hyderabad, India \\ ${ }^{2}$ Department of Clinical Research, Sahajanand Medical Technologies Pvt. Ltd., Surat, India \\ Email: karunmd@gmail.com
}

Received 5 June 2014; revised 4 July 2014; accepted 3 August 2014

Copyright (C) 2014 by authors and Scientific Research Publishing Inc.

This work is licensed under the Creative Commons Attribution International License (CC BY).

http://creativecommons.org/licenses/by/4.0/

(c) (i) Open Access

\section{Abstract}

Background: Diphtheria is still endemic in India due to inadequate immunization. The incidence of myocarditis is higher in these patients. Objectives: The objective of this study was to study clinical profile, clinical outcomes as well as immunization status of the patients diagnosed with diphtheria myocarditis in Indian scenario. Methodology: This prospective observational study was carried out in one of the tertiary care hospital of south India from August 2011 to December 2012. A total of 33 cases with clinically confirmed diagnosis of diphtheria myocarditis were enrolled depending upon the inclusion and exclusion criteria of the study. Electrocardiography and 2-dimensional echocardiography was done at the time of admission and repeated when required. Results: The most common age group affected is $\mathbf{5}$ - 10 years, with no sex difference in occurrence. Only 1 patient, out of 33 patients, was adequately immunized. Asymptomatic myocardial involvement (with only changes in electrocardiogram) was seen in 21 patients whereas 12 patients were symptomatic. The average duration of resolution of electrocardiographic changes was 4 - 6 weeks. It should be noted that out of 28 patients who developed conduction abnormalities, 24 patients died. Temporary pacemaker support was given for 8 patients, of whom only one patient recovered. The patient was followed till hospital discharge. Conclusion: The mortality associated with diphtheria myocarditis is higher in Indian population. As diphtheria can be prevented by adequate vaccination, efforts should be maximized for $90 \%$ coverage with three doses of diphtheria toxoid in children below one year of age and immunity towards it should be maintained by booster doses.

\section{Keywords}

Diphtheria Myocarditis, Clinical Outcomes, Epidemiology 


\section{Introduction}

The incidence of diphtheria in the developed countries has steadily declined following effective immunization program since the 1920's. However, resurgence had been observed mainly due to waning immunity in adults. In developing countries, the disease is still endemic and responsible for high case fatality [1] [2].

Corynebacterium diphtheria produces exotoxins which cause DNA fragmentation and cytolysis by inhibiting elongation factor-2 activity in protein synthesis in addition to damage to conduction tissue [3] [4]. The myocardium also shows hyaline degeneration and necrosis. This results in development of myocarditis in patients with diphtheria. Myocarditis may occur in about $10 \%$ - 25\% of patients with respiratory diphtheria and it is considered the most serious complication with high reported mortality [5] [6]. The risk of developing cardiac toxicity is proportional to the severity of local infection. Diphtheria myocarditis is frequently manifested by arrhythmias that can cause sudden death if not managed properly. The patients with cardiac involvement may be asymptomatic (changes in electrocardiogram (ECG) and/or raised cardiac enzymes) or symptomatic (features of heart failure) [7].

In India, diphtheria still remains endemic and associated with fulminant complications and mortality [8]. Several factors like inadequate vaccine coverage, poor socio-economic status, delayed reporting, and delayed administration or unavailability of diphtheria antitoxin further contribute to high mortality [9]. Even though, there was higher prevalence of the disease in India, we found the scarcity of literature which focused on the incidence, clinical profile as well as clinical outcomes of myocarditis in the patients diagnosed with diphtheria myocarditis. So, we design the study to address clinical profile, clinical outcomes as well as immunization status of the patients diagnosed with diphtheria myocarditis in Indian scenario.

\section{Methodology}

\subsection{Study Design and Patient Population}

This was a prospective, single-center and observational study. A total of 33 cases with clinically confirmed diagnosis of diphtheria myocarditis, shifted from "Sir Ronald Ross Institute of Tropical and Communicable Diseases”, Hyderabad, India, from August, 2011 to December, 2012 to department of cardiology, Osmania general hospital, Hyderabad, India for further management were enrolled in the study. The study protocol was approved by institutional ethics committee. The written informed consent was obtained from all the patients or from the parents of the patient.

Inclusion criteria: All the patients admitted to the hospital with clinically confirmed diagnosis of diphtheria myocarditis were included in the study.

Exclusion criteria: (1) Patients with structural heart disease; (2) patients with background history of diabetes, hypertension, heart disease; and (3) patients with previous ECG changes were excluded from this study.

The detailed medical history and clinical examination reports were collected using pre-defined case-record form. The immunization detail was obtained from the parents or the attendant of the patient. Each patient was monitored closely for any development of shortness of breath, palpitation, and chest discomfort, and hypotension. ECG-12 lead and 2-dimensional echocardiography was done at the time of admission and repeated as and when required. Temporary pacemaker was inserted in all patients who developed complete heart block. The patient was followed till hospital discharge.

We had adopted previously published criteria for abnormal ECG in patients with diphtheritic myocarditis as follow: arrhythmia, abnormal Q waves, repolarization abnormalities, ST segment elevation (elevation $>1 \mathrm{~mm}$ in at least two chest lead or one limb lead), T-wave inversion (except in leads V1 and aVR) isoelectric T waves and QTc interval ( $>0.39$ s for men and $>0.41$ s for women), arterioventricular block, bundle branch block and complete heart block.

\subsection{Statistical Analysis}

Statistical analysis was performed using Statistical Package for Social Sciences (SPSS; Chicago, IL, USA) program, version 15. Continuous data are expressed as mean + standard deviation.

\section{Results}

Thirty-three patients with diphtheritic myocarditis were studied during the study period. The demographic and 
clinical characteristics of the patients are outlined in Table 1 . Out of 33 patients 18 were males, 15 were females. The age group, most commonly affected, was 5 - 10 years (15 patients) which was followed by age group 10 - 15 years (8 patients). The common clinical features were fever $(n=32)$, throat pain $(n=31)$ and difficulty in swallowing $(\mathrm{n}=30)$.

\subsection{Immunization Status of the Patient}

The immunization status of the patients enrolled in the study has been shown in Table 2. Only 1 patient, out of 33 patients, was adequately immunized.

\subsection{Electrocardiographic Changes among Patients with Diphtheria Myocarditis}

Asymptomatic myocardial involvement (with only ECG changes) was seen in 21 patients. The average duration of resolution of ECG changes was 4 - 6 weeks. There were 12 patients who were symptomatic. Among the symptomatic patients, 4 patients developed frank features of heart failure. Table 3 shows myocardial abnormali

Table 1. Demographic and clinical characteristics of the patients enrolled in the study.

\begin{tabular}{lc}
\hline \multicolumn{1}{c}{ Characteristics } & No. of patients N = 33 \\
\hline Age, years (Mean) & 11.24 \\
$<5$ years & $2(6.06 \%)$ \\
5 - 10 years & $15(45.45 \%)$ \\
10 - 15 years & $8(24.24 \%)$ \\
15 - 20 years & $7(21.21 \%)$ \\
$>20$ years & $1(3.03 \%)$ \\
Gender & \\
Male, n (\%) & $18(54.55 \%)$ \\
Clinical features & \\
Fever, n (\%) & $32(96.97 \%)$ \\
Throat pain, n (\%) & $31(93.94 \%)$ \\
Difficulty in swallowing, n (\%) & $30(90.91 \%)$ \\
Bull Neck, n (\%) & $19(57.58 \%)$ \\
Shortness of breath, n (\%) & $15(45.45 \%)$ \\
Renal failure, n (\%) & $12(36.36 \%)$ \\
Nasal regurgitation, n (\%) & $8(24.24 \%)$ \\
Hoarseness, n (\%) & $6(18.18 \%)$ \\
Palpitation, n (\%) & $1(3.03 \%)$ \\
Stridor, n (\%) & $1(3.03 \%)$ \\
Limb weakness, n (\%) & $1(3.03 \%)$ \\
\hline
\end{tabular}

Table 2. Immunization status of the patients.

\begin{tabular}{|c|c|c|c|c|}
\hline \multirow{2}{*}{ Age group } & \multirow{2}{*}{ No. of patients } & \multicolumn{3}{|c|}{ Immunization status } \\
\hline & & Immunized adequately & Inadequately & Unimmunized \\
\hline$<5$ years & 2 & - & - & 2 \\
\hline 5 - 10 years & 15 & 1 & 1 & 13 \\
\hline $10-15$ years & 8 & - & 1 & 7 \\
\hline 15 - 20 years & 7 & - & - & 7 \\
\hline$>20$ years & 1 & - & - & 1 \\
\hline
\end{tabular}


Table 3. Electrocardiographic abnormalities among patients with diphtheria myocarditis.

\begin{tabular}{lc}
\hline \multicolumn{1}{c}{ Cardiac abnormality } & No. of patients \\
\hline ST changes & 1 \\
T-wave inversion & 3 \\
Abnormal conduction & 6 \\
Left bundle branch block & 6 \\
Right bundle branch block & 5 \\
Complete heart block & 1 \\
Right bundle branch block + Left bundle branch block & 2 \\
Right bundle branch block + Complete heart block & 4 \\
Left bundle branch block + Complete heart block & 1 \\
Left bundle branch block + Right bundle branch block + Complete heart block & 3 \\
Inappropriate sinus tachycardia + Left bundle branch block & 3 \\
\hline
\end{tabular}

ties observed in the patients. The conduction abnormality was observed in 28 patients. Left bundle branch block (LBBB) and complete heart block (CHB) were observed in 6 patients and 5 patients respectively. There was 1 patient who experienced LBBB, right bundle branch block (RBBB) and CHB.

\subsection{Clinical Outcomes}

It should be noted that out of 28 patients who developed conduction abnormalities, 24 patients died. The detail has been shown in Figure 1. Total 24 patients died, of whom 12 patients died due to malignant arrhythmias (Ventricular tachycardia/Ventricular fibrillation), 11 patients died due to respiratory arrest, 1 patient died due to supraventricular tachycardia. Temporary pacemaker support was given for 8 patients, of whom only one patient recovered.

\section{Discussion}

In India, the incidence of diphtheria myocarditis varies from $16 \%$ to $66 \%$ [10] [11]. Havaldar et al. had carried out the study for the period of 10 years and he found that myocarditis was becoming major cause of death (8 out of 16 deaths) in patients with diphtheria by gradually replacing major cause of death i.e. laryngeal obstruction or post-tracheostomy complications [12]. Myocarditis is reported to be the only independent predictor of death in patients with diphtheria [11]. The study conducted in India between January 1998 to December 2012 also demonstrated myocarditis was responsible to $66.6 \%$ deaths in patients with diphtheria [8]. So to determine the clinical profile and clinical outcomes of patients with diphtheritic myocarditis, we carried out this study.

In our study, the majority of the cases were noted in the age group of 5 - 10 years (45.5\% patients) and there was no sex difference in the occurrence of the disease.

It has been proved that diphtheria vaccine is one of the major approaches for the control and prevention of diphtheria (at least $90 \%$ coverage). The recommended schedule for immunization (for diphtheria) in India is as follow: For infants - a series of four doses given at two, four, six, and 15 - 18 months of age. A fifth shot, or booster dose, is recommended at 4 - 6 years of age, unless the fourth dose was given late (after the fourth birthday). Because immunity to diphtheria wanes with time, individuals should receive a booster dose of tetanusdiphtheria toxoid every ten years.

In India, major reason for higher incidence of diphtheria in children may be inadequate immunization. It has been observed in our study also that out of 33 patients of the study, only 1 patient was adequately immunized whereas 30 patients were unimmunized. Majority of the unimmunized patients belonged to the age group of 5 10 years.

The clinical signs of cardiac involvement in diphtheria are non-specific. There were 28 patients who experienced conduction abnormality and it is noteworthy that out of these 28 patients, 24 patients died. All the patients who developed LBBB died during hospitalization. The study carried out by M. M et al. also showed that the patients with diphtheria who developed myocarditis presented with conduction blocks and arrhythmias [8]. 


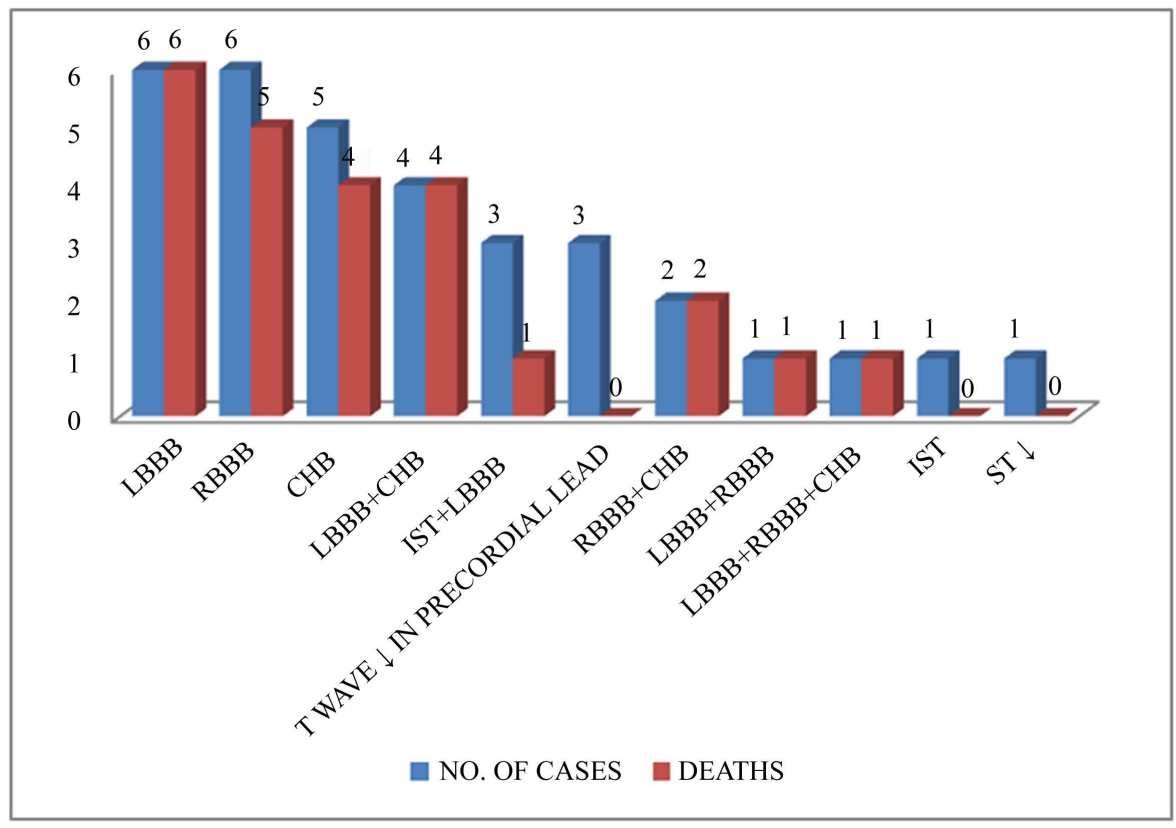

Figure 1. Mortality of the patients experienced myocardial abnormality. (CHB = complete heart block; IST = inappropriate sinus tachycardia; LBBB = left byndle branch block; RBBB $=$ right bundle branch block; ST $\downarrow=\mathrm{ST}$ depression; $\mathrm{T}$ wave $\downarrow$ in precordial lead $=\mathrm{T}$ wave depression in precordial lead).

Celik et al. also demonstrated that the patients with LBBB and T wave inversion at hospital discharge had lower survival rates than that of the patients without these ECG changes in their long term follow-up [13]. They even identified LBBB and T wave inversion as the independent predictors of survival in diphtheritic myocarditis. In our study, the mortality rate of diphtheria myocarditis was $72.7 \%$ which is higher than that of the study carried out by Stockins et al. in which mortality rate was $46 \%$ [14].

\section{Conclusion}

The incidence of diphtheria has increased in recent years and the most common age group affected is 5 - 10 years, with no sex difference in occurrence. Most of the patients with diphtheria presented with asymptomatic myocarditis and those who presented with either LBBB alone or with combination of other conduction abnormalities depicted high mortality rate.

\section{References}

[1] Galazka, A.M. and Robertson, S.E. (1995) Diphtheria: Changing Patterns in the Developing World and the Industrialized World. European Journal of Epidemiology, 11, 107-117. http://dx.doi.org/10.1007/BF01719955

[2] Mattos-Guaraldi, A.L., Moreira, L.O., Damasco, P.V. and Hirata Jr., R. (2003) Diphtheria Remains a Threat to Health in the Developing World-An Overview. Memórias do Instituto Oswaldo Cruz, 98, 987-993. http://dx.doi.org/10.1590/S0074-02762003000800001

[3] Collier, R.J. (1975) Diphtheria Toxin: Mode of Action and Structure. Bacteriological Reviews, 39, 54-85.

[4] Hadfield, T.L., McEvoy, P., Polotsky, Y., Tzinserling, V.A. and Yakovlev, A.A. (2000) The Pathology of Diphtheria. The Journal of Infectious Diseases, 181, S116-S120. 10.1086/315551 http://dx.doi.org/10.1086/315551

[5] Singh, J., Harit, A.K., Jain, D.C., Panda, R.C., Tewari, K.N., et al. (1999) Diphtheria Is Declining but Continues to Kill Many Children: Analysis of Data from a Sentinel Centre in Delhi, 1997. Epidemiology and Infection, 123, 209-215. http://dx.doi.org/10.1017/S0950268899002812

[6] Hoyne, A. and Welford, N.T. (1934) Diphtheritic Myocarditis: A Review of 496 Cases. The Journal of Pediatrics, 5, 642-653. http://dx.doi.org/10.1016/S0022-3476(34)80043-1 http://dx.doi.org/10.1016/S0022-3476(34)80043-1

[7] Reidermann, M.I. (1996) Cardiac Complications in Adult Diphtheria: Analysis of 212 Cases. Praxis (Bern 1994), 85, 
$1647-1651$.

[8] M, M. and M, R. (2014) Diphtheria in Andhra Pradesh—A Clinical-Epidemiological Study. International Journal of Infectious Diseases, 19, 74-78.

[9] Singhal, T., Lodha, R., Kapil, A., Jain, Y. and Kabra, S.K. (2000) Diphtheria—Down but Not Out. Indian Pediatrics, 37, 728-38.

[10] Havaldar, P.V., Sankpal, M.N. and Doddannavar, R.P. (2000) Diphtheritic Myocarditis: Clinical and Laboratory Parameters of Prognosis and Fatal Outcome. Annals of Tropical Paediatrics, 20, 209-215.

[11] Jayashree, M., Shruthi, N. and Singhi, S. (2006) Predictors of Outcome in Patients with Diphtheria Receiving Intensive Care. Indian Pediatrics, 43, 155-160.

[12] Havaldar, P.V. (1992) Diphtheria in the Eighties: Experience in a South Indian District Hospital. Journal Of Indian Medical Association, 90, 155-156.

[13] Celik, T., Selimov, N., Vekilova, A., Kursaklioglu, H., Iyisoy, A., et al. (2006) Prognostic Significance of Electrocardiographic Abnormalities in Diphtheritic Myocarditis after Hospital Discharge: A Long-Term Follow-Up Study. Annals of Noninvasive Electrocardiology, 11, 28-33. http://dx.doi.org/10.1111/j.1542-474X.2006.00062.x

[14] Stockins, B.A., Lanas, F.T., Saavedra, J.G. and Opazo, J.A. (1994) Prognosis in Patients with Diphtheric Myocarditis and Bradyarrhythmias: Assessment of Results of Ventricular Pacing. British Heart Journal, 72, 190-191. http://dx.doi.org/10.1136/hrt.72.2.190 
Scientific Research Publishing (SCIRP) is one of the largest Open Access journal publishers. It is currently publishing more than 200 open access, online, peer-reviewed journals covering a wide range of academic disciplines. SCIRP serves the worldwide academic communities and contributes to the progress and application of science with its publication.

Other selected journals from SCIRP are listed as below. Submit your manuscript to us via either submit@scirp.org or Online Submission Portal.
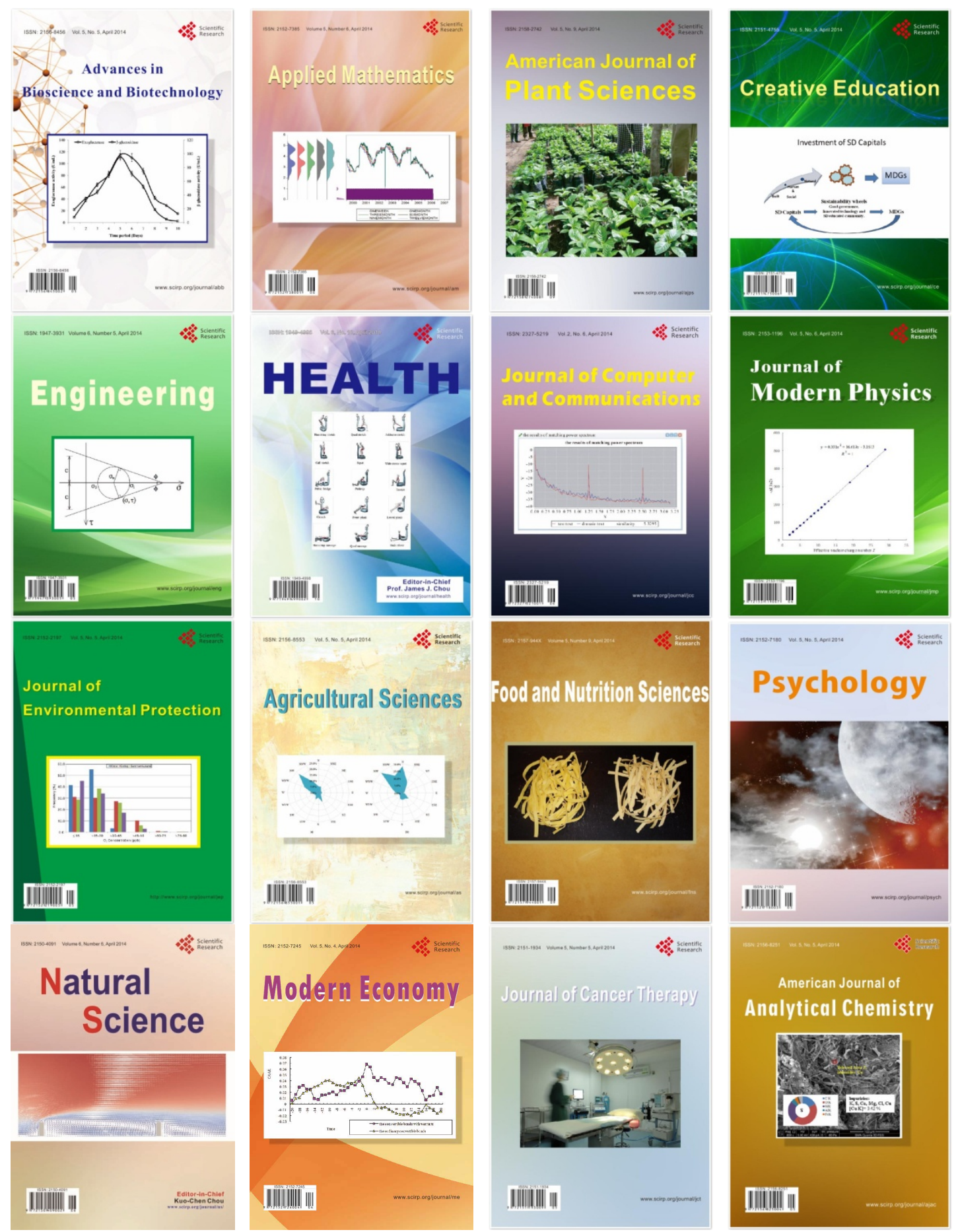